\title{
A COMPETÊNCIA INFORMACIONAL COMO DISCIPLINA CURRICULAR NA FORMAÇÃO DE BIBLIOTECÁRIOS NA ESPANHA E NO BRASIL
}

\author{
Marta Leandro da Mata* \\ Departamento de Ciência da Informação. Universidade Estadual de Londrina. Brasil. \\ Helen de Castro Silva Casarin** \\ Departamento de Ciência da Informação. Universidade Estadual Paulista. Brasil. \\ Miguel Ángel Marzal*** \\ Departamento de Biblioteconomía y Documentación. Universidade Carlos III de Madrid. Espanha.
}

\begin{abstract}
Resumo: Objetivou-se verificar como as disciplinas de competência informacional têm sido abordadas nos cursos de Informação e Documentação na Espanha e de Biblioteconomia no Brasil, de forma a caracterizar os principais conteúdos. Nesse sentido, realizou-se uma pesquisa de caráter qualitativo e documental, analisando os currículos e os planos de ensino destes cursos em ambos os países. Verificou-se que a abordagem destas disciplinas nos cursos brasileiros é divergente, enquanto que, no caso espanhol, estão focados na formação de futuros educadores/formadores. Concluiu-se que no Brasil a inserção da temática da competência informacional está em consolidação. Na Espanha, há maior incidência de cursos que contemplam este conteúdo e nota-se certo consenso na forma como esta temática é abordada nos cursos. Uma aproximação das discussões e trocas entre os dois países pode ser enriquecedora e fortalecer o tema principalmente no Brasil.

Palavras-chave: Competência informacional; alfabetização informacional; biblioteconomia; curso de informação e documentação; currículo acadêmico.
\end{abstract}

Título: LA ALFABETIZACIÓN INFORMACIONAL COMO DISCIPLINA CURRICULAR EN LA FORMACIÓN DE BIBLIOTECARIOS EN ESPAÑA Y BRASIL.

Resumen: Se plantea como objetivo verificar cómo las disciplinas sobre competencia informacional son abordadas en el Grado de Información y Documentación en España y de Biblioteconomía en Brasil, con el fin de caracterizar sus principales contenidos. El estudio utilizó una investigación cualitativa y documental, analizando los currículos y planes de estudios de estos cursos en los dos países. Se encontró que el contenido de estos cursos en Brasil es divergente mientras que en España, se centran en la formación de futuros educadores/formadores. Se concluyó que en Brasil, la integración de la temática de competencia informacional está en consolidación. En España hay una mayor incidencia de cursos que incluyen este contenido, y se nota un cierto consenso sobre cómo se aborda tal cuestión. Una aproximación entre los debates e intercambios de los dos países puede ser enriquecedora y fortalecer el tema, principalmente en Brasil.

Palabras clave: Competencia informacional; alfabetización informacional; biblioteconomía; información y documentación; currículo universitario.

Title: THE INFORMATION LITERACY HOW TO DISCIPLINE IN THE CURRICULUM LIBRARIANS TRAINING IN SPAIN AND BRAZIL.

Abstract: The aim of this study was to how the disciplines of information literacy have been addressed in the courses of Information and Documentation in Spain and Librarianship in Brazil, in order to characterize the main contents. In this sense, there was a research of a qualitative nature and documentary, analyzing the curricula and syllabi of these courses in both countries. Using content analysis, it was found that the content of these modules in Brazilian courses is divergent, while in the Spanish case they are focused on the formation of future educators. It was concluded that in Brazil the integration of information literacy topics is still being consolidated. In Spain, there is a higher incidence of courses that include this content, and it is noticeable that there is a certain consensus on how this issue is addressed in courses. Promoting exchange and further discussion between the two countries may be enriching, and strengthen the subject, especially in Brazil.

Keywords: Information literacy; librarianship; curricula; undergraduate courses.

\footnotetext{
*martalm@uel.br

***helenc@marilia.unesp.br

***mmarzal@bib.uc3m.es
}

Recibido: 04-03-2015; 2a versión: 24-03-2016; aceptado: 27-04-2016.

MATA, M.L.; SILVA CASARIN, H.C. y MARZAL, M.A. A competência informacional como disciplina curricular na formação de bibliotecários na Espanha e no Brasil. Anales de Documentación, 2016, vol. 19, $\mathrm{n}^{\circ} 2$. Disponible en: http://dx.doi.org/10.6018/analesdoc.19.2.222171. 


\section{INTRODUÇÃO}

A competência informacional é apresentada, em todos os níveis de ensino, com uma nova proposta de modelo educacional, formal e informal, que pode ser manifestada por meio de um conjunto de "boas práticas". Ela possibilita aos estudantes a construção de uma aprendizagem permanente, visando à capacitação do sujeito no que se refere ao planejamento de estratégias para a construção do seu saber, à tomada de decisão para avaliação em uma nova competência leitora-escritora e à inclusão social para o desenvolvimento de um espírito solidário, de modo a propiciar um comportamento sob parâmetros deontológicos sólidos e a supressão dos riscos da brecha digital e da ruptura social (Marzal, 2009).

Essa competência pode ser desenvolvida em indivíduos de diferentes faixas etárias e em variados níveis de ensino, por meio de programas, contemplando conteúdos acerca do universo informacional, durante o período de escolarização. Tais programas podem ser realizados desde as séries iniciais do ensino fundamental até o ensino superior, devendo estar, preferencialmente, integrados ao planejamento educacional, ao currículo e aos planos de ensinos.

Entretanto, um fator determinante para possibilitar a implementação de tal proposta é a existência de profissionais capacitados. A princípio, o bibliotecário é um dos profissionais mais preparados para trabalhar a competência informacional, pois sua formação acadêmica contempla conteúdos acerca da necessidade de informação dos usuários (comportamento informacional; serviço de referência), de fontes de informação, tratamento, organização e recuperação da informação, de ética no uso da informação e de disseminação da informação por intermédio de diferentes meios e suportes. Estes conteúdos, no entanto, são tratados em diversas disciplinas, cujos objetivos específicos não abrangem necessariamente a competência informacional.

Para que o bibliotecário auxilie as pessoas no desenvolvimento da competência informacional, o profissional, além de desenvolver suas próprias competências, deve saber planejar, preparar e ministrar os conteúdos, de acordo com o público-alvo, em diferentes situações e utilizando recursos variados.

Conforme Pinto e Uribe Tirado (2010), os profissionais da informação graduados e os que irão formar-se possuem o desafio de aprender, compreender e ensinar as competências informacionais aos indivíduos, de forma a integrar os conhecimentos alcançados durante o desenvolvimento de suas atividades com novos paradigmas, modelos e métodos que requerem a formação baseada em competências. O bibliotecário deverá desenvolver sua própria competência informacional para resolver problemas complexos relacionados com a gestão da informação e para poder formar outros profissionais e usuários. Complementa Campal García (2006), que o bibliotecário é considerado o facilitador dos processos de aprendizagem relacionados à informação.

Assim sendo, uma questão sobre a formação deste profissional deve ser objeto de reflexão: os cursos que formam bibliotecários têm incluído disciplinas específicas de competência informacional? Quais os conteúdos abordados nestas disciplinas? Assim, partiu-se da tese de que a inserção de uma disciplina de competência informacional nos cursos de graduação em Informação e Documentação e de Biblioteconomia pode auxiliar os graduandos a compreenderem o significado da Competência Informacional e a serem capazes de desenvolver programas desta natureza em variados tipos de instituições no momento de sua atuação profissional.

Na visão de Marzal (2004), a formação do profissional bibliotecário deve responder aos desafios de reorientação de sua formação - pensando nas exigências sociais, adaptando-se aos novos modelos de unidades de informação -, assimilando a competência informacional como objeto de sua própria aprendizagem e como exigência para o exercício da profissão, exercendo sua função docente nas aulas/sessões de programas desta natureza.

Com ênfase na formação do bibliotecário, o presente artigo relata parte dos resultados de um estudo que teve como principal objetivo analisar a abordagem realizada nas disciplinas de alfabetização informacional/competência informacional nos cursos de Informação e Documentação na Espanha e de Biblioteconomia no Brasil, buscando-se caracterizar os temas contemplados nos planos de ensino dessas disciplinas no que se refere ao conceito, ao tipo de programa (estrutura, etapas, etc.), ao ambiente (tipo de biblioteca ou centro de recursos e aprendizagem) e aos recursos de aprendizagem (uso de ambiente presencial e/ou virtual), bem como o caráter das disciplinas (obrigatório ou opcional). 


\section{A COMPETÊNCIA INFORMACIONAL: DESAFIO E OPORTUNIDADE PARA OS BIBLIOTECÁRIOS}

\subsection{A competência informacional em Educação}

Abordar a competência informacional dentro do âmbito acadêmico implica determinar, ao menos a efeito de uma análise acadêmica, seu alcance epistemológico, definindo a relação entre alfabetización en información (alfabetização em informação), alfabetización informacional ou informativa (alfabetização informacional ou informativa) e competencias en información ou informacional (competências em informação ou informacional).

Uma primeira perspectiva é válida para o objetivo deste trabalho. Na América Latina, visto que alfabetización tem sentido pejorativo e refere-se à competência leitora-escritora, prefere-se usar o termo "competencia". Na Europa, por outro lado, o maior protagonismo acadêmico tende para o termo "alfabetización". No mundo anglo-saxão, o termo skill refere-se a "modelos", e literacy, a "programas de ensino de competência informacional". Contudo, no contexto laboral, há uma perspectiva distinta: na Espanha, bibliotecários e documentalistas preferem incidir em competências, enquanto acadêmicos e pesquisadores preferem alfabetização.

Sem dúvida, sob uma ótica de fundamentação epistemológica e para efeito deste trabalho, não parece necessário insistir nesta indefinição. A alfabetização informacional é o modelo, o método, a especialidade ou a área acadêmica; a competência informacional é, por sua vez, seu objeto e seu campo de estudo. Sendo assim, a pesquisa aplicada, os cursos, os programas, as ações, os planos concernem às competências em informação, enquanto os projetos de investigação, a fundamentação conceitual e a modelização são do âmbito da alfabetização informacional.

De acordo com Licea de Arenas, Gómez Hernández e Valles Valenzuela (2009, p. 217), a competência informacional se refere às competências para avaliar e usar criticamente as fontes de informação e aplicar seu conteúdo às atividades cotidianas dos indivíduos. Conforme Gómez Hernández (2009, p. 106), o serviço de Competência Informacional é, em geral, de função educativa e de apoio à aprendizagem em todos os níveis de ensino.

Complementa Gómez Hernández (2007), que do ponto de vista profissional, discorre-se sobre a competência informacional para denominar os serviços planejados pela biblioteca com a finalidade de facilitar que os usuários adquiram habilidades mencionadas. Em questões teóricas e investigativas, designa-se a alfabetização informacional como uma área disciplinar cujo objeto seria o desenvolvimento de padrões, modelos pedagógicos, critérios de avaliação e estratégias políticas para a melhoria das competências informacionais dos cidadãos.

Na Espanha, de forma empírica e por aplicação prática, a distinção parece clara. No currículo universitário de Grado de Información y Documentación (Graduação em Informação e Documentação) é patente a denominação de alfabetización informacional, com algumas variações. Por outro lado, os cursos de especialização ou atualização profissional utilizam, com maior frequência, o termo competência informacional e, raramente, técnicas, destrezas ou habilidades informacionales.

Compreendidas as diferenças, ambos os termos serão utilizados no presente trabalho, devido à distinção que se faz do conceito no Brasil e na Espanha ${ }^{1}$. Ademais, o uso dos dois termos deve-se ao fato de nossa análise descansar em uma dupla dimensão: a incorporação da "alfabetización informacional" como uma nova especialidade acadêmica necessária à formação dos profissionais de Informação e Documentação e de Biblioteconomia; e a projeção desta voltada para o espaço e o campo de trabalho destes profissionais, sendo denominada neste ambiente como "competência informacional".

É imprescindível, portanto, uma definição do objeto deste estudo sobre competências em educação e competências informacionais. Na Educação, as competências devem mobilizar conhecimentos, procedimentos e atitudes, desde os conteúdos de aprendizagem para a tomada de decisão ante uma hipótese científica ou um desafio profissional (Carrera; Marín, 2011). A mobilização de "recursos" diz respeito tanto aos recursos internos, referidos às faculdades do educando (saber-fazer, saber-ser), como aos externos, referidos aos materiais didáticos, aos recursos de infraestrutura, à qualificação dos docentes e à avaliação.

A projeção das competências no modelo educativo competencial, particularmente no Espacio Europeo de Educación Superior (EEES), tem sido realizada, fundamentalmente, mediante o "Projeto Tuning", o qual surgiu em 2000, com finalidade de proporcionar uma base para a melhora da qualidade da educação superior. Trata-se de uma ferramenta que permite a cooperação entre universidades e configura-se como um pilar de estratégias acadêmicas para a consecução de algumas competências educativas. 
O projeto Tuning converteu-se em uma referência mundial. Obteve projeções visíveis na Rússia $<$ http://www.tuningrussia.org/>, nos Estados Unidos - especificamente, nos Estados de Minnesota, Indiana e Utah $<$ http://tuningusa.org/About.aspx $>$-, nas repúblicas centro-asiáticas (TuCAHEA - <http://www.tucahea.org/>), na África $<$ http://www.tuningafrica.org/> e no Japão. Tal projeto tem a Tuning Academy como sua entidade gestora, que publica o Tuning Journal for Higher Education < http://www.tuningjournal.org/index.php/tuning $>$ desde novembro de 2013.

O projeto Tuning tem um impacto inegável na América Latina, já que foi iniciado durante os anos 2004-2007 e projetou-se como modo de inovação educativa e social durante os anos 2011-2013<http://www.tuningal.org/>. Além disso, a referida iniciativa concretizou-se com a apresentação de uma metodologia para o desenvolvimento do modelo na chamada "Tuning América Latina", realizada no México-DF, em 2007. Nesse sentido, recomendou-se o imprescindível apoio financeiro para amparar estratégias metodológicas conjuntas, em suas distintas modalidades, como, por exemplo, formação de professores e interoperabilidade de titulações.

A aplicação de um modelo educativo baseado em competências para programas educativos específicos foi pedagogicamente fundamentado na Teoría de la elaboración sobre competências. Esta referência teórica baseia-se no Construtivismo, o qual propõe o desenho instrucional de sequências didáticas a partir de análise de conteúdo e análise de tarefas. Posto isto, os programas devem inserir-se em um currículo, que reproduz as grandes orientações de um sistema educativo (Jonnaert et al., 2006), cujos elementos definidores são seus conceitos de conhecimento e de inteligência, assim como a demanda social. Como resultado, os profissionais serão preparados para conceber global e totalmente as situações que irão enfrentar, de modo a atender as necessidades dos empregadores.

Diante disso, é necessário ressaltar o progresso da Web Semântica, que implicou um novo modo de aprender em Web (do e-learning ao m-learning) e um novo método para converter a grande quantidade de informação digital disponível em conhecimento. A necessidade de conhecer e saber na Web demandou uma combinação progressiva de informação-conhecimento-saber, que assentou o binômio "competências" e "informação". As competências informacionais, em vista disso, voltaram-se ao desenvolvimento de conhecimentos e habilidades na gestão da informação, no uso e na aplicação dos conteúdos, na edição e na compreensão do conhecimento obtido.

O progresso da Web Semântica implica um novo modo de aprender em Web (do e-learning ao m-learning) e um novo método para converter a grande quantidade de informação digital disponível em conhecimento. A necessidade de conhecer e saber na Web demandou uma combinação progressiva de informação-conhecimento-saber, que assentou o binômio "competências" e "informação". As competências informacionais, em vista disso, voltaram-se ao desenvolvimento de conhecimentos e habilidades na gestão da informação, no uso e na aplicação dos conteúdos, na edição e na compreensão do conhecimento obtido.

\subsection{A percepção da competência informacional como objetivo profissional: o caso da Espanha}

O desenvolvimento da universidad gerencial caracterizada, entre outros aspectos, pela excelência por objetivos e resultados, faz com que seus cursos, inclusive o de Informação e Documentação, propiciem a inserção profissional de seus egressos de forma exitosa, como indicador de excelência acadêmica. Nessa perspectiva, a competência informacional, entendida como um fator determinante para a inovação, para a eliminação de brechas e de fomento para a inclusão, tem se convertido em um objetivo profissional interessante para os estudantes na seleção de estudos e para os acadêmicos na estrutura curricular. Naturalmente, não deve fundamentar-se por percepções subjetivas ou premonição de tendências, senão mediante estudos prospectivos.

Na Espanha, desde a década de 1990, acadêmicos e associações profissionais elencaram estudos (encuestas), com a finalidade de conhecer a percepção de professores, alunos, egressos, empregadores e associações profissionais a respeito da formação e das expectativas relativas à profissão. Também foram reunidos estudos sobre a demanda laboral, a partir de anúncios de ofertas de trabalho veiculadas em distintos meios de comunicação ou em convênios de cooperação educativa.

Todavia, não se trata, no momento, de fazer um estudo profundo da evolução no tempo, dos resultados e das discussões acerca desses trabalhos. Trata-se de apresentar seus efeitos com foco no objetivo do presente artigo: mostrar a visão atual, a visão do futuro, as expectativas e as tendências futuras na formação e no trabalho do profissional da informação, com especial atenção à função das competências informacionais. Para isto, é necessário proceder à análise de três perspectivas: 


\section{a) A análise das competências informacionais do ponto de vista acadêmico: percepção de docentes e egressos}

A análise baseia-se em projetos que avaliam a opinião dos egressos dos cursos de Informação e Documentação das universidades públicas da Comunidade de Madri (Espanha) sobre a adequação da formação universitária ao mercado de trabalho (Moreiro et al., 2008). Dentre os sujeitos da pesquisa, 82,9\% declararam-se razoavelmente satisfeitos com os conteúdos teóricos abordados nos cursos. No entanto, apontaram como deficiências a excessiva especialização teórica, as carências tecnológicas, o divórcio entre mercado de trabalho e a formação acadêmica, a necessidade de compreender melhor a gestão das unidades de informação e a gestão de conteúdos. A respeito da formação prática, $62,4 \%$ consideraram-na boa ou normal, enquanto $23,9 \%$ consideraram-na deficiente.

Existe, portanto, a propensão a demandar uma formação profissional superior com forte conexão laboral e, não, uma formação científica. Diante disso, o uso insuficiente de ferramentas para gestão documental, a ausência de laboratórios, de conteúdos temáticos informáticos, de ensino de inglês, de orientação a oposições e a inserção laboral deficiente foram apontados como as maiores deficiências durante a formação. Nesse panorama, destacou-se que, na opinião dos egressos, no que tange às atividades que eles deveriam desenvolver, a "formação de usuários" é a sétima de um elenco de 33. Os entrevistados também afirmaram que dedicam 4,6\% de seu tempo para esta atividade. Contudo, quando foi perguntado aos egressos que competência de Euroreferencial parecia-lhes mais relevante, responderam "busca de informação", enquanto "formação e ações pedagógicas" recebeu 3,47\% das indicações, ficando na $24^{\mathrm{a}}$ posição entre as 28 competências perguntadas.

\section{b) Perspectiva dos empregadores}

Entre as importantes publicações existentes sobre o tema, a análise ficará detida naquelas que têm as ofertas de trabalho como objeto de investigação, por sua atualidade (Abadal et al., 2012). A partir do universo estatístico formado por essas ofertas, devido à crise econômica de $2012,87 \%$ das ofertas são privadas, incluindo uma ampla variedade de empresas privadas $(80 \%)$, em especial portais web, consultorias, empresas de trabalho temporário.

Ao analisar o perfil solicitado, as ofertas vinculadas à Biblioteconomia e Documentação passaram, de 2009 a 2012 , de $62 \%$ a $27 \%$ em bibliotecas e de $14 \%$ a $4 \%$ nos arquivos. Frente a isto, foi incrementado a oferta em marketing e comunicação, de $6 \%$ a $32 \%$, e gestão de conteúdo, de $7 \%$ a 26\%. Em 2011-2012, os perfis mais solicitados foram community manager, técnico em marketing online e mídia social, gestor de conteúdos web (content curator) e documentalista. Os investigadores estabeleceram, em suas análises, uma categoria, "gestão cultural e educação", que se manteve estável: de 7,36\% a 7,24\%. Algo preocupante, sem dúvida, refere-se à titulação requerida: $48 \%$ de ofertas não requerem nenhuma titulação específica (incremento de 7\%), enquanto $37 \%$ requerem titulação superior (incremento de $23 \%$ ). As ofertas que requerem titulação específica decresceram de $36 \%$ a $15 \%$.

\section{c) A perspectiva das associações profissionais}

Também existe um repertório suficiente e muito relevante de informes e publicações por parte de associações profissionais espanholas, mas também por sua atualidade, a análise será detida ao informe de perspectiva da profissão, publicado pela Federación Española de Sociedades de Archivística, Biblioteconomía, Documentación y Museística (FESABID, 2011). Além de sua atualidade, o informe inclui uma dimensão muito relevante para nosso estudo: se acadêmicos, egressos e empregadores não parecem deter-se prioritariamente (se identificam e analisam, mas não dão prioridade) às competências informacionais, como um fator laboral destacável, as associações profissionais manifestam uma opinião diferente.

A partir das ofertas de trabalho, evidencia-se que o perfil específico de uma graduação não é exigido, mas perfis relacionados a postos de trabalho específicos e concretos (Tejada Artigas; Chacón Jarén; Moreiro-González, 2014), com perfis generalistas ou específicos. Para uma definição de perfil generalista para profissionais da informação do século XXI, pode-se recorrer à Special Libraries Association (2003): "usa la información estratégicamente en su trabajo para potenciar la misión de la organización, mediante el desarrollo, despliegue y dirección de recursos de información y servicios. Utiliza las TIC como herramienta crítica para lograr objetivos". Atendendo a esta tendência, na Espanha, o Consejo de Cooperación Bibliotecaria deu boas vindas ao Grupo de Trabajo de Perfiles Profesionales (GT14), que identificou e descreveu 21 perfis profissionais, precisamente o P10 foi reconhecido como Especialista en formación de usuario y alfabetización informacional.

No estudo de FESABID, de 2011, foi aplicado um questionário em que se perguntava aos profissionais sobre a visão presente da profissão (sendo valor 0 em total discordância e valor 4 para completo acordo). As respostas que 
vão de 3 a 4 são: "minha forma de trabalhar tem mudado muito"; "necessito reciclar meus conhecimentos com frequência", "necessito de formação permanente na formação em novas tecnologias", "formação permanente em processos técnicos", "em gestão e planejamento" e "em novos serviços", "é preciso a colaboração com outros profissionais", "as TIC facilitam meu trabalho" (a mais: 3,7), "me adapto com facilidade às TIC". A maioria considera que sua formação é suficiente, porém não a adequada. A formação universitária é objeto de avaliação negativa para os participantes do estudo, com valor dois, em especial entre os que trabalham em empresas privadas e os mais jovens com tempo de serviço.

Sobre as necessidades formativas, a concordância é muito grande em relação às TIC. Sobre a visão de futuro, utilizando os mesmos parâmetros que para a visão do presente, as respostas de 3 a 4 foram: "meu perfil profissional terá caráter híbrido", "compromisso ético com cidadãos", "permanecerei me considerando profissional da informação", "os espaços presenciais seguirão sendo necessários", "os serviços telemáticos serão mais empregados", "as bibliotecas oferecerão recursos on-line" (alta: 3,7), "serviços por dispositivos móveis". Nota-se que todas as respostas são muito altas ao referir-se a aspectos tecnológicos. Perguntou-se ainda se os profissionais da informação serão formadores em informação. Em uma escala de 0 a 5, foram obtidas as seguintes respostas: $0(1,26 \%) ; 1(3,35 \%)$; $2(10,40 \%) ; 3(31,89 \%) ; 4(49,97 \%)$; não sabe/não contesta $(3,14 \%)$.

Junto às perguntas de metodologia quantitativa para profissionais e egressos, aplicou-se a técnica de Delphi aos profissionais, seguindo uma metodologia qualitativa. Foi perguntado se os profissionais irão atuar como mediadores de aprendizagem e formadores (0 nada, 5 muito), e 3,8 foi a média geral, sendo 3,5 entre arquivistas, 3,8 em bibliotecas, 3,7 entre docentes, 4,1 em documentação.

É importante destacar a Red de Bibliotecas Universitarias Españolas (REBIUN), que fornece diretrizes para as bibliotecas com vistas a potencializar a cooperação e realização de projetos conjuntos e atua com quatro linhas estratégicas, destacando-se a segunda linha, referente à aprendizagem e à investigação (CRAI), que visa integrar de forma progressiva as competências informáticas e informacionais (CI2) nos diferentes cursos da universidade como estratégia educativa para o desenvolvimento de capacidades válidas para toda vida; Potencializar a biblioteca como um agente dinamizador da inovação docente da universidade e incrementar o uso dos recursos informacionais desde as diferentes plataformas educativas virtuais das universidades; Desenvolver e melhorar o modelo de biblioteca universitária como Centro de Recursos de Aprendizagem e Investigação (CRAI), analisando as necessidades de docência, aprendizagem e pesquisa dos usuários, criando e personalizando novos serviços e espaços bibliotecários, estabelecendo marcos de colaboração e integração aos serviços universitários (REBIUN, 2016).

Considera-se que na Espanha existe uma preocupação das entidades e associações profissionais de Documentação com as questões relacionadas à competência informacional e com seus respectivos rumos, de forma a tentar buscar subsídios para a implementação dos programas de Competências informáticas e informacionais (CI2 ${ }^{2}$ ).

\subsection{Competência informacional e os bibliotecários: uma análise a partir do contexto brasileiro}

No ano de 2000, no contexto brasileiro, iniciaram-se as discussões em torno da competência informacional, principalmente no ambiente acadêmico, dando origem a diversas publicações (Caregnato, 2001; Campello, 2003; Dudziak, 2003). No âmbito profissional, a forma predominante de divulgação/conhecimento sobre o tema entre os bibliotecários foi a partir de eventos, palestras, oficinas e workshops, com a participação de associações profissionais e de professores acadêmicos.

Com ênfase na atuação dos bibliotecários em programas de competência informacional, cabe destacar dois pontos no contexto brasileiro: a) a formação acadêmica/profissional em Biblioteconomia e; b) o papel das associações profissionais no que se refere ao tema.

Quanto às competências exigidas pelas instituições empregadoras e sua relação com a competência informacional, enfatiza-se a falta de informações organizadas sistematicamente e atualizadas acerca do mercado de trabalho do bibliotecário. A falta de uma fonte de informação específica que contenha tais dados, bem como a extensão territorial do país influi na dificuldade de organização destas informações.

\section{a) Formação acadêmica dos bibliotecários}

O período de formação acadêmica torna-se oportuno à disseminação da competência informacional e de suas práticas, vistas como um processo de ensino-aprendizado referente às fontes de informação destinadas aos usuários. 
Em dois documentos oficiais, que orientam o projeto político pedagógico dos cursos de Biblioteconomia no Brasil, encontram-se conteúdos relacionados com a competência informacional.

Nas Diretrizes Curriculares Nacionais do Ministério da Educação (BRASIL, 2001), recomenda-se que os cursos visem à formação de competências, entre as quais "[...] elaborar, coordenar, executar e avaliar planos, programas e projetos”. Já os Referenciais Curriculares Nacionais dos Cursos de Bacharelado (BRASIL, 2010, p. 9) sugerem temas que devem ser abordados no curso, a saber: "[...] Serviços de Referência; Comunicação; Formação de Leitores; Competência em Informação [...]".

Conforme Mata (2014), nos cursos de Biblioteconomia do Brasil, em 10 dos 39 cursos existentes, existem disciplinas específicas de competência em informação, como pode ser observado nos resultados apresentados no presente artigo.

\section{b) Mobilização das instituições brasileiras quanto à competência informacional}

Uma das principais instituições que tem voltado seus esforços à competência informacional é a Federação Brasileira de Associações de Bibliotecários, Cientistas da Informação e Instituições ${ }^{3}$ (FEBAB). Por meio desta, foi oferecido um curso de competência informacional, em 2010 e em 2014, ambos na modalidade de ensino à distância, destinado a profissionais da área de Biblioteconomia.

A FEBAB, junto a algumas associações, promove o Congresso Brasileiro de Biblioteconomia e Documentação (CBBD), trazendo discussões acerca do tema. No ano de 2005 , foi realizado um workshop ${ }^{4}$ sobre a competência informacional, visando a promover a reflexão e o debate sobre as estratégias de ação para viabilizar maiores informações e conhecimentos sobre essa área em esfera nacional. Entre as questões apresentadas para o debate, incluía-se: "Qual a importância da competência em informação ou information literacy para bibliotecários e educadores?" (CBBD, 2005).

O CBBD tem sido um espaço de mobilização para discussão do tema, visto que, em 2009, durante a realização do evento, foi promovido um "Atelier de Competência em Informação". No CBBD, em 2011, ocorreu o "Seminário de Competência em Informação", tendo como consequência a publicação da "Declaração de Maceió" (2010). Também no CBBD, em 2013, ocorreu o "20 Seminário de Competência em Informação". Neste mesmo ano, a FEBAB publicou o e-book "Competência em informação: de reflexões às lições aprendidas", organizado por Belluzzo e Feres (2013).

No CBBD, realizado em 2013, constatou-se, por meio dos relatos de experiência dos profissionais bibliotecários, que existem programas relacionados ao treinamento/capacitação/educação de usuários, no entanto, estes não são especificamente de competência informacional. Há muitos trabalhos que realizam uma avaliação diagnóstica de grupos específicos, apontando a necessidade de implementação de programas desta natureza (Mata, 2014).

No Seminário de Competência em Informação, que ocorreu em 2015, os trabalhos apresentados neste de evento resultaram na publicação do e-book intitulado "Competência em Informação: teoria e práxis", coordenado por Simeão e Belluzzo (2015).

Em geral, a FEBAB vem criando espaços de mobilização para discussão por meio de workshops, ciclos de palestras, seminários, oficinas, entre outros, assim como tem realizado parcerias com instituições internacionais que atuam vigorosamente com o tema, como a The International Federation of Library Associations and Institutions (IFLA). Essas ações colocam o tema em evidência nos âmbitos profissional e acadêmico da área, possibilitando aos bibliotecários ter contato com o tema em questão, de modo que compreendam o seu conceito, a sua importância e incentivem a realização de programas desta natureza nas instituições em que estiverem atuando.

\subsection{As tendências da profissão}

A partir dos estudos prospectivos de mercado de trabalho, para atender aos objetivos profissionais, convém deterse não só ao perfil laboral que se pede nas áreas muito próximas ao campo dos profissionais da informação, mas sobre toda titulação universitária que é exigida, observando que as principais solicitações e os requisitos de titulação são:

- Gestores de conteúdos Web. Solicitam-se, geralmente, informáticos, ou seja, graduados em cursos relacionados à informática.

- Designer de conteúdos Web. Solicitam-se profissionais da área de informática.

- Criadores de conteúdos Web. Solicitam-se, geralmente, jornalistas, filólogos ou especialistas. 
- Intermediários organização-clientes (promoção e comunicação): community managers, experts em mídia social, experts em SEO, etc. Com a solicitação, geralmente, de informáticos com experiência em marketing.

- Responsáveis por projetos de gestão documental (controle e acompanhamento). Com a requisição, geralmente, de profissionais com formação prévia e especialização em Informação e Documentação.

- Desenvolvedores de conteúdos educativos. Solicitam-se, sobretudo, informáticos ou especialistas em elearning, com formação e/ou experiência.

- Responsáveis por programas educativos (entidades públicas e privadas). Solicitam-se profissionais de todos os tipos, com formação e/ou experiência.

Se a constatação das ofertas de trabalho, uma vez mais, manifesta que os profissionais da informação encontram-se escondidos/esfumaçados/diluídos entre outros profissionais para realizar tarefas que poderiam lhes ser próprias, incluída a formação e educação em competências informacionais, o The Economist Intelligence Unit Report (2006), "Foresight 2020: Economic, industry and corporate trends", mostra como o âmbito profissional de Informação e Documentação/Biblioteconomia encontra-se na Gestão do Conhecimento e, dentro dela, a função primordial da formação e educação em competências informacionais.

\section{PROCEDIMENTOS METODOLÓGICOS DO ESTUDO DE CAMPO}

A presente investigação caracteriza-se como uma pesquisa de cunho exploratório, documental e comparativo. Primeiramente, procedeu-se a identificação das instituições de ensino que oferecem o curso de Biblioteconomia no Brasil e o curso de Informação e Documentação na Espanha. No caso brasileiro, foi realizada uma consulta ao Portal do Ministério da Educação - MEC $^{5}$. Verificou-se que existiam 39 cursos de Biblioteconomia funcionando regularmente no Brasil, dos quais quatro estão localizados na Região Centro-Oeste, 10 na Região Nordeste, três na Região Norte, 17 na Região Sudeste e cinco no Sul do país. A identificação das instituições de ensino que ofereciam o curso de Informação e Documentação na Espanha ocorreu por meio do Portal do Ministerio de Educación, Cultura y Deporte - MECD ${ }^{6}$. Foram identificados 12 cursos, distribuídos em nove comunidades autônomas, a saber: um em Andaluzia, um em Aragão, dois em Castela e Leão, dois em Catalunha, um em Extremadura, um na Galícia, dois em Madri, um em Murcia e um em Valência.

Num segundo momento, os sites oficiais dos cursos brasileiros e espanhóis foram consultados, a fim de extrair as informações sobre os currículos dos cursos. Quando não havia informações disponíveis, os coordenadores dos cursos foram contatados por correio eletrônico e/ou por telefone.

Foram obtidas as matrizes curriculares de $92 \%$ dos cursos brasileiros, isto é, 36 do total de 39 cursos de Biblioteconomia existentes no país. Os três cursos $(8 \%)$ que não participaram da pesquisa não dispunham de informações sobre o currículo em seus sites, e os respectivos coordenadores ou departamentos não responderam aos emails nem forneceram os documentos solicitados. Todos os sites dos cursos espanhóis dispunham de informações atualizadas sobre os currículos de seus cursos.

Foi realizada a análise de conteúdo de Bardin (2010), desde a análise flutuante das matrizes curriculares dos cursos de Biblioteconomia brasileiros, de forma a identificar disciplinas que possuíam a nomenclatura "competência informacional" e seus equivalentes, como "competência em informação", "alfabetização informacional", "letramento informacional", "infoeducação". Na Espanha, ao realizar a análise flutuante, encontrou-se disciplinas com as seguintes denominações: alfabetización informacional ou alfabetizatización en información.

$\mathrm{Na}$ análise dos conteúdos abordados nas disciplinas identificadas de ambos os países, seguiu-se realizando a análise de conteúdo (Bardin, 2010), consistindo na categorização dos resultados, que pode ser considerada como:

A categorização é uma operação de classificação de elementos constitutivos de um conjunto por diferenciação

$e$, seguidamente, por reagrupamento segundo o género (analogia), com critérios previamente definidos. As categorias são rubricas ou classes, as quais reúnem um grupo de elementos (unidades de registro, no caso da análise de conteúdo) sob um título genérico, agrupando esse efectuado em razão das características comuns dos elementos. (Bardin, 2010, p. 145).

Foram definidas a priori quatro categorias para análise: conceito, programa, ambiente e recursos de aprendizagem. Estas categorias foram definidas a partir da macrodefinição de "competência informacional" proposta por Uribe Tirado (2009). No Quadro I, estão especificadas as categorias e suas respectivas abordagens: 


\begin{tabular}{|c|c|}
\hline Categorias & Definição \\
\hline Conceito & $\begin{array}{c}\text { Definição ou significado da competência informacional e suas variações } \\
\text { terminológicas. }\end{array}$ \\
\hline Programas & $\begin{array}{c}\text { Estrutura e etapas de um programa de competência informacional; inclui } \\
\text { planejamento, objetivo, missão, avaliação, entre outros. }\end{array}$ \\
\hline $\begin{array}{c}\text { Recursos } \\
\text { aprendizagem }\end{array}$ & $\begin{array}{l}\text { Ferramentas, materiais e recursos utilizados para desenvolvimento de atividades e } \\
\text { programas de competência informacional; inclui o uso de ambientes de aprendizagem } \\
\text { virtuais. }\end{array}$ \\
\hline
\end{tabular}

Quadro I. Categorias de análise das disciplina/planos de ensino.

A apresentação e análise dos resultados foram estruturadas em duas subseções, 4.1, referente aos cursos de Informação e Documentação da Espanha; e 4.2, referente aos cursos de Biblioteconomia do Brasil. Cada subseção contém as categorias mencionadas no Quadro 1. Quanto ao conteúdo abordado nas disciplinas, foram consultados os planos de ensino, a ementa e os objetivos de cada disciplina, sendo os resultados organizados em quadros com o nome de cada plano de ensino/curso/universidade substituído por letras, como por exemplo, plano de ensino A, plano de ensino B, e, assim por diante.

Os quadros possuem os termos encontrados nos planos de ensino de cada disciplina de competência em informação analisada, porém quando há ausência de conteúdos, estes são representados por traços “-”. Observa-se que por uma questão ética, os nomes dos cursos e das disciplinas foram omitidos. Os resultados serão apresentados a seguir.

\section{APRESENTAÇÃO E ANÁLISE DOS RESULTADOS}

\subsection{Alfabetização informacional como especialidade acadêmica das competências informacionais}

Na Espanha, cinco dos 12 cursos de Informação e Documentação existentes oferecem disciplinas de alfabetização informacional. Diferentemente do que ocorre com as disciplinas brasileiras, a terminologia utilizada nessas disciplinas é consensual, ou seja, são mencionados os termos "alfabetização informacional" ou "alfabetização em informação" e a abreviatura ALFIN. Quatro disciplinas são optativas e uma é de formação básica. Todas são presenciais, mas utilizam uma plataforma de aprendizagem virtual; em quatro delas especifica-se a utilização do Moodle.

Com relação aos conteúdos abordados nestas disciplinas, verificou-se, primeiramente, se o conceito de alfabetização informacional é mencionado nas disciplinas.

\begin{tabular}{|l|l|}
\hline Plano de ensino & Conteúdo abordado \\
\hline A & Conceito de alfabetização informacional \\
\hline B & Conceitos básicos \\
\hline C & Conceitos de alfabetização informacional \\
\hline D & Conceito \\
\hline E & Conceitos de ALFIN \\
\hline
\end{tabular}

Quatro das cinco disciplinas incluem o conceito alfabetização informacional. No plano de ensino da disciplina A, analisa-se a origem e evolução do conceito, definição de alfabetização informacional, desde uma perspectiva teórica, normativa e de aplicação de boas práticas - com análise de sua inserção em pesquisas no âmbito acadêmico - até sua difusão e projeção social. Na disciplina C, incluem-se os conceitos de "alfabetização informacional" e "alfabetização digital", suas capacitações, tendências e práticas internacionais para o desenvolvimento deste serviço. O objetivo da disciplina $\mathrm{D}$ especifica que se pretende que os alunos compreendam os conceitos básicos de alfabetização informacional e sua aplicação no contexto biblioteconômico. Nos objetivos da disciplina E, verifica-se que os alunos deverão explicar, compreender e descrever os termos e os conceitos de ALFIN.

No plano de ensino B, no entanto, os conceitos a que a disciplina se refere não estão relacionados à alfabetização informacional, mas aos seus conteúdos, ou seja, fontes de informação, recuperação da informação, estratégias de busca e normalização documentária.

Verificou-se também se os planos de ensino abordam conteúdos acerca de programas de alfabetização informacional, visto que quatro das cinco disciplinas analisadas incluem este conteúdo, conforme o quadro a seguir. 


\begin{tabular}{|c|c|}
\hline Plano de ensino & Conteúdo abordado \\
\hline A & Projeção de programas de alfabetização informacional. \\
\hline B & - \\
\hline C & $\begin{array}{c}\text { Elaboração e execução de programas de competência } \\
\text { informacional. }\end{array}$ \\
\hline D & $\begin{array}{c}\text { Planejar e avaliar serviços de alfabetização informacional } \\
\text { no contexto das bibliotecas. }\end{array}$ \\
\hline E & $\begin{array}{c}\text { Planejar um programa ALFIN em uma unidade de } \\
\text { informação. }\end{array}$ \\
\hline
\end{tabular}

Quadro III. Programas de alfabetização informacional na Espanha.

No plano de ensino A, são abordados conteúdos relacionados a modelos e normas de alfabetização informacional, a conceitos, à dimensão e à eficácia da avaliação em programas, considerando-a elemento imprescindível para demonstrar a aquisição das competências informacionais pelos participantes. No plano de ensino C, incluem-se estudos do nível dos destinatários destes programas, contextos de aplicação (presenciais ou avançados), atividades de cooperação entre docentes em disciplinas e trabalhos de pesquisa, recursos econômicos, materiais ou financeiros e avaliação. O plano de ensino D contém os modelos e as normas de alfabetização informacional recomendadas para uso no programa e a avaliação das atividades realizadas. No E, encontrou-se menção aos programas nos resultados de aprendizagem que se pretende que os alunos alcancem, visando à capacitação para o planejamento e para a implementação de programas de ALFIN, levando-se em consideração as diferentes necessidades dos usuários e dos ambientes de aplicação. No plano de ensino B, não foram encontradas referências aos programas.

Outro aspecto analisado nos planos são os recursos de aprendizagem que podem ser utilizados em programas e atividades de alfabetização informacional. Conforme demonstra o Quadro VI, três dos cinco planos analisados apresentam este conteúdo.

\begin{tabular}{|l|l|}
\hline Plano de ensino & Conteúdo abordado \\
\hline A & Materiais educativos para a alfabetização informacional. \\
\hline B & - \\
\hline C & $\begin{array}{c}\text { Tutoriais online, FAQ ou cursos online, blogs, wikis, } \\
\text { redes sociais. }\end{array}$ \\
\hline D & Elaboração de ferramentas e tutoriais. \\
\hline E & - \\
\hline
\end{tabular}

Quadro IV. Recursos de aprendizagem virtual para programas de ALFIN.

O plano de ensino A possui conteúdo voltado para a aprendizagem de recursos eletrônicos, com a finalidade de o aluno colocar em prática sua competência escrita e a leitura digital nos materiais considerados imprescindíveis de serem usados em um programa desta natureza. A disciplina inclui tipologia de recursos web educativos para alfabetização informacional, tipologias específicas para saber na web, tais como repositórios digitais educativos.

Tanto no $\mathrm{C}$ quanto no $\mathrm{D}$, abordam-se tutoriais e ferramentas de aprendizagem virtual, sendo que, no $\mathrm{D}$, os resultados de aprendizagem preveem o conhecimento das principais ferramentas educacionais e tecnológicas para atividades de programação da ALFIN.

\subsection{A competência informacional como disciplina curricular nos cursos de Biblioteconomia do Brasil}

No contexto brasileiro, observa-se que 10 cursos de Biblioteconomia (25,6\% do total) possuem disciplinas específicas de competência informacional ou com nomenclaturas equivalentes, como "competência em informação", "letramento informacional" ou "infoeducação", sendo que sete disciplinas são de caráter obrigatório e três são optativas. Todas são oferecidas na modalidade de ensino presencial.

Em relação aos conteúdos abordados nessas disciplinas, verificou-se que oito das 10 disciplinas identificadas incluem o conceito de competência informacional, conforme Quadro V. Há uma preocupação dos cursos em apresentar uma visão ampla ao aluno, abordando os diferentes conceitos e o histórico do tema. No caso do plano de ensino da disciplina B, que não inclui o conceito, verifica-se que as práticas de leitura e de mediação da informação são enfatizadas. Este enfoque aparece também na disciplina A, cuja ênfase é na leitura; cabe destacar, porém, que o conceito é abordado. $\mathrm{Na}$ disciplina $\mathrm{H}$, a ementa revela o foco na didática pedagógica e o conceito não é destacado. 


\begin{tabular}{|c|c|}
\hline Plano de ensino & Conteúdo abordado \\
\hline A & $\begin{array}{cccc}\begin{array}{c}\text { Leitura } \\
\text { conceituais. }\end{array} & \text { competência informacional: } & \text { questões } \\
\end{array}$ \\
\hline $\mathrm{B}$ & - \\
\hline $\mathrm{C}$ & $\begin{array}{l}\text { Revisar os conceitos fundamentais relacionados ao } \\
\text { processo de letramento informacional. }\end{array}$ \\
\hline $\mathrm{D}$ & O conceito de competência informacional. \\
\hline $\mathrm{E}$ & Conceitos e aspectos históricos da Infoeducação. \\
\hline $\mathrm{F}$ & $\begin{array}{l}\text { Apresenta uma visão abrangente dos principais conceitos } \\
\text { e abordagens da competência informacional. }\end{array}$ \\
\hline $\mathrm{G}$ & Saberes informacionais: abordagens. \\
\hline $\mathrm{H}$ & - \\
\hline I & $\begin{array}{l}\text { Competência informacional: conceituação, aspectos } \\
\text { teóricos e práticos. }\end{array}$ \\
\hline $\mathrm{J}$ & $\begin{array}{l}\text { Aspectos conceituais, históricos e metodológicos da } \\
\text { competência informacional. }\end{array}$ \\
\hline
\end{tabular}

Quadro V. Conceito de competência informacional nos planos de ensino brasileiros.

No plano de ensino da disciplina G, que menciona saberes informacionais, os conteúdos abordados são: alfabetização informacional, information literacy, educação para a informação.

Verificou-se ainda se as disciplinas contemplavam os programas de competência informacional, ou seja, a forma como a competência informacional pode ser trabalhada com os usuários.

\begin{tabular}{|c|l|}
\hline Plano de ensino & Conteúdo abordado \\
\hline A & - \\
\hline B & $\begin{array}{l}\text { Desenvolvimento assistido da competência informacional. } \\
\text { Preparação de usuários para as práticas da educação } \\
\text { continuada. }\end{array}$ \\
\hline C & Avaliar os programas de letramento informacional. \\
\hline D & Habilidades informacionais em diferentes contextos. \\
\hline E & - \\
\hline F & $\begin{array}{l}\text { Aborda os aspectos relacionados ao desenvolvimento da } \\
\text { competência informacional, entre eles programas, parâmetros e } \\
\text { formas de avaliação. }\end{array}$ \\
\hline G & Programas de infoeducação: conceito, metodologia, gestão. \\
\hline H & Planejamento de ensino. \\
\hline I & $\begin{array}{l}\text { Programas, Modelos e projetos de desenvolvimento da } \\
\text { competência informacional. }\end{array}$ \\
\hline
\end{tabular}

Quadro VI. Programas de competência informacional nos planos de ensino do Brasil.

Observou-se que sete das 10 disciplinas abordam este conteúdo. Na disciplina $\mathrm{D}$, há uma menção ao desenvolvimento de habilidades informacionais em diferentes contextos, contudo, percebe-se que o objetivo desta disciplina é reforçar as competências informacionais dos alunos dos cursos de Biblioteconomia por intermédio da realização de pesquisas. Na disciplina $\mathrm{H}$, o foco é o planejamento das aulas. Nos planos de ensino $\mathrm{A}$, E e I não são abordados conteúdos referentes aos programas.

Os recursos de aprendizagem a serem utilizados em programas e atividades de competência informacional formam outra categoria de análise. Conforme demonstra o Quadro VII, apenas duas disciplinas mencionam os recursos de aprendizagem. 


\begin{tabular}{|c|c|}
\hline Plano de ensino & Conteúdo abordado \\
\hline $\mathrm{A}$ & - \\
\hline $\mathrm{B}$ & - \\
\hline $\mathrm{C}$ & $\begin{array}{l}\text { Produção de recursos educacionais abertos de letramento } \\
\text { informacional. }\end{array}$ \\
\hline $\mathrm{D}$ & - \\
\hline$E$ & - \\
\hline $\mathrm{F}$ & - \\
\hline G & 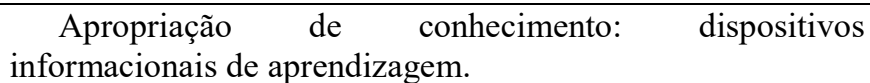 \\
\hline $\mathrm{H}$ & - \\
\hline I & - \\
\hline $\mathrm{J}$ & - \\
\hline
\end{tabular}

Quadro VII. Recursos de Aprendizagem na disciplina de competência informacional.

Este conteúdo, apesar de ser instrumental e de extrema importância em um programa de ensino, tem sido pouco abordado na maioria dos cursos brasileiros. Em uma das disciplinas, foi mencionado o seguinte conteúdo: a) objetos de aprendizagem, os recursos de livre acesso; b) mídias: experimentos, softwares, vídeos e áudios; c) levantamento de softwares livres para produção de conteúdos e; d) produção e avaliação dos recursos educacionais.

De forma geral, em uma disciplina de competência informacional, questões acerca de seu histórico-conceitual, de estruturação de programas instrucionais e de recursos de aprendizagem são temas fundamentais, porquanto possibilitam aos alunos uma maior uma compreensão referente à competência informacional e sua implementação nos locais de atuação.

\section{CONCLUSÕES}

Os bibliotecários devem ser preparados para atuar em programas de competência informacional em variados tipos de instituição. Em vista disso, os cursos de graduação possuem um papel importante no preparo deste profissional e, muitas vezes, são os responsáveis pelo primeiro contato de seus alunos com o tema.

No Brasil, embora o tema da competência informacional seja recomendado em documentos oficiais, poucos cursos seguem esta recomendação, pois somente 10 dos 39 cursos existentes possuem disciplinas específicas sobre do tema. Contudo, deve-se ressaltar que há outras disciplinas e atividades dos cursos que abordam o tema de forma significativa. A maioria dessas disciplinas é de caráter obrigatório, o que garante maior atendimento aos alunos.

A inserção dessas disciplinas nos cursos é considerada um importante avanço nesta área, observando-se que o tema é relativamente recente no país. Ainda não há um consenso sobre a terminologia. Ademais, os conteúdos, nestas disciplinas, são variados e, muitas vezes, divergentes, abordando, por exemplo: desenvolvimento de habilidades informacionais, leitura, mediação da informação, processos de busca e uso da informação, objetos de aprendizagem, didática, dispositivos informacionais referentes à escola. Nesse sentido, há necessidade de uma maior discussão e ampliação do debate sobre a competência informacional, já que, ao contrário do contexto espanhol, há ainda poucos cursos que incluem a disciplina em seu currículo.

Na Espanha, a inserção da disciplina de Alfabetización informacional (competência informacional) está presente em cinco dos 12 cursos existentes. Entretanto, a maioria destas disciplinas é de caráter optativo, o que contrasta com a realidade do país, uma vez que existe aceitação satisfatória do tema por parte da classe bibliotecária e por haver programas desta natureza em variadas instituições de ensino superior. Verificou-se ainda que há consistência na terminologia e nos conteúdos abordados nas disciplinas nos cinco cursos estudados, mesmo que estas sejam de caráter opcional. Considera-se que o principal objetivo destas disciplinas é a formação de futuros educadores/formadores em programas de competência informacional. Há uma preocupação em contemplar conteúdos relacionados aos ambientes de aprendizagem virtuais, incluindo o uso de diversas plataformas e objetos de aprendizagem online, redes sociais, etc. A utilização da plataforma moodle como ferramenta de ensino nas próprias disciplinas, ainda que estas sejam presenciais, também auxilia no desenvolvimento de suas habilidades específicas para a utilização de recursos de aprendizagem. Já no Brasil, apenas uma disciplina inclui este conteúdo, revelando um ponto a ser explorado ainda pelos cursos. 
Diante deste panorama, acredita-se que a competência informacional vem ganhando cada vez mais espaço, tanto no Brasil quanto na Espanha, ainda que possuam algumas divergências. Uma aproximação das discussões e trocas entre os dois países pode ser enriquecedora e fortalecer o tema, principalmente no Brasil, ainda que guardadas as diferenças sociais, econômicas, políticas e, inclusive, territoriais entre ambos.

\section{RECOMENDAÇÕES}

De forma geral, para subsidiar a elaboração da ementa e do conteúdo programático das disciplinas de competência informacional dos cursos de Biblioteconomia e de Informação e Documentação, recomenda-se o uso dos parâmetros de competência informacional existentes na literatura da área, por exemplo, da ACRL (2011; 2012); e Lau (2006), voltados para o planejamento de programas, dos padrões da ACRL (2000), AASL (1998), ANZIIL/Bundy (2004) e Kuhlthau (2004) direcionados para o conteúdo abordado junto aos estudantes em programas desta natureza. Ressaltase que existem vários parâmetros voltados tanto para o planejamento das fases dos programas quanto para o conteúdo a ser aplicado, tais padrões foram desenvolvidos por instituições especializadas no tema em alguns países.

O uso destes parâmetros é importante, pois estes possuem uma base conceitual consistente, fruto de amplas reflexões e de debates que podem ser adotados na elaboração do conteúdo destas disciplinas. A adoção de documentos elaborados por entidades associativas e científicas na elaboração de currículos dos cursos é comum em diversas áreas (a área de Engenharia de Produção, por exemplo, adota o documento chamado matriz de competências que foi elaborado pela Associação de Engenharia de Produção). Estes documentos são complementares às recomendações oficiais. A partir desta base comum, os cursos podem acrescentar e/ou aprofundar os itens que considerarem necessários, a partir de seu próprio contexto e dos objetivos de seu currículo.

\section{NOTAS}

\footnotetext{
${ }^{1}$ No Brasil, não há diferenciação entre a terminologia e o significado de competência em informação no contexto profissional e acadêmico.

2 Podem ser encontradas informações específicas a respeito da CI2 neste endereço eletrônico: <http://www.ci2.es/>.

$3<$ http://www.febab.org.br/>.

${ }^{4}$ O workshop foi ministrado pela Profa. Regina C. B. Belluzzo, que também tem oferecido vários cursos de Competência em Informação para profissionais da informação.

${ }^{5}$ Portal do Ministério da Educação no Brasil, disponível em:<http://emec.mec.gov.br/>, consultado em junho de 2012.

${ }^{6}$ Portal do Ministério <http://www.mecd.gob.es/portada-mecd/>, consultado em junho de 2013.
}

\section{REFERÊNCIAS}

ABADAL, E. et al. Mercado laboral de profesionales de la información: evolución de la oferta y de los perfiles ocupacionales». BiD: textos universitaris de biblioteconomia $i$ documentació, desembre, núm. 29. $<$ http://bid.ub.edu/29/abadal2.htm $>$ [Consulta: 12 jun. 2014].

AMERICAN ASSOCIATION OF SCHOOL LIBRARIES - AASL. (1998). Information literacy standards for students learning. Disponível em: <http://www.ala.org/aasl/ip_nine.html> [Consulta: 01 out. 2014].

ASSOCIATION OF COLLEGE AND RESEARCH LIBRARIES. Characteristics of programs of information literacy that illustrate best practices: a guideline. Chicago: ALA: 2012 . Disponível em: $<$ http://www.ala.org/acrl/standards/characteristics> [Consulta: 20 abr. 2013].

ASSOCIATION OF COLLEGE AND RESEARCH LIBRARIES. Guidelines for Instruction Programs in Academic Libraries. Chicago: ALA, 2011. Disponível em: <http://www.ala.org/acrl/standards/guidelinesinstruction> [Consulta: 20 abr. 2013].

ASSOCIATION OF COLLEGE AND RESEARCH LIBRARIES. Information literacy competency for higher education. Chicago: ALA, 2000. Disponível em: <http://www.ala.org/acrl/ilcomstan.html $>$ [Consulta: 06 jan. 2012].

BARDIN, L. Análise de conteúdo. Lisboa: Edições 70, 2010.

BELLUZZO, R.C.B. y FERES, G.G. Competência em informação: de reflexões às lições aprendidas. São Paulo: FEBAB, 2013.

BRASIL. Ministério da Educação. Diretrizes Curriculares Nacionais dos cursos de Filosofia, História, Geografia, Serviço Social, Comunicação Social, Ciências Sociais, Letras, Biblioteconomia, Arquivologia e Museologia, 2001. Disponível em: <http://portal.mec.gov.br/cne/arquivos/pdf/CES0492.pdf> [Consulta: 12 set. 2014].

BRASIL. Referenciais curriculares nacionais dos cursos de bacharelado e licenciatura. Brasília, DF: Ministério da Educação; Secretaria do Ensino Superior, 2010. 
BUNDY, A. Australian and New Zealand information literacy framework: principles, standards and practice. Adelaide: Australian and New Zealand Institute for Information Literacy, 2004. Disponível em: $<$ http://www.caul.edu.au/infoliteracy/InfoLiteracyFramework.pdf $>$ [Consulta: 26 nov. 2014].

CAMPAL GARCÍA, M.F. Dossier: Practicando ALFIN. Educación y Biblioteca, 2006, nº 156, p. 48-141.

CAMPELLO, B.S. O movimento da Competência Informacional: uma perspectiva para o letramento informacional. Ciência da Informação, 2003, vol. 32, nº 3, p. 28-37.

CAREGNATO, S.E. O desenvolvimento de habilidades informacionais: o papel das universidades no contexto da informação digital em rede. Revista de Biblioteconomia e Documentação, 2000, vol. 8, p. 47-55.

CARRERA, C. y MARÍN, R. Modelo pedagógico para el desarrollo de competencias en educación superior. Revista Actualidades Investigativas en Educación, 2011, vol. 11, nº 1, p. 1-32.

Congresso Brasileiro de Biblioteconomia, Documentação e Ciência da Informação, Curitiba, Julio 17-24, 2005. Curitiba, Paraná: Febab, 2005.

Declaração de Maceió Sobre A Competência Informacional. In: Congresso Brasileiro de Biblioteconomia, Documentação e Ciência da Informação, Maceió, Agosto, 7-10, 2011. Maceió: FEBAB, 2011. Disponível em: $<$ http://www.cfb.org.br/UserFiles/File/Declaracao\%20de\%20Maceio\%20sobre\%20Competencia $\% 20$ em $\% 20$ Infor macao.pdf $>$ [Consulta: 15 dez. 2014].

DUDZIAK, E.A. Information Literacy: princípios, filosofia e prática. Ciência da Informação, 2003, vol. 32, nº 1, p. 23-35.

FEBAB. Competência informacional para bibliotecários. São Paulo: FEBAB, 2010. Disponível em: $<$ http://www.febab.org.br/> [Consulta: 02 jun. 2010].

FEBAB. Workshop "competência em informação" (information literacy). In: Congresso Brasileiro de Biblioteconomia e Documentação, 21., Curitiba: FEBAB, 2005. Disponível em: <www.febab.org.br/CBBD_WORKSHOP_RELATORIO_FINAL.doc> [Consulta: 22 maio 2010].

FESABID. Estudio FESABID sobre los profesionales de la información. Prospectiva de una profesión en constante evolución. Madrid: FESABID, 2011.

GÓMEZ HERNÁNDEZ, J.A. Alfabetización informacional: cuestiones básicas. Anuário ThinkEPI, 2007, p. 43-55.

GÓMEZ HERNÁNDEZ, J.A. Aprender a enseñar competencias informacionales a los usuarios: avances en la formación profesional en España. Anuário ThinKePI, 2009, p. 106-113.

JONNAERT, P. et al. Revisión de la competência como organizadora de los programas de formación: hacia un desempeño competente. Ginebra: Oficina Internacional de Educación BIE/UNESCO, 2006.

KUHLTHAU, C.C. Como usar a biblioteca na escola: um programa de atividades para o ensino fundamental. Tradução e adaptação de Bernadete Santos Campello et al. 2. ed. Belo Horizonte: Autêntica, 2004.

LAU, J. Learning Assessment. In: Guidelines on Information Literacy for lifelong learning. Universidad Veracruzana, Unidad de Servicios Bibliotecarios y de Información, 2006. Boca del Río, Veracruz, México Reviwed, 2006. cap. 9, p. 42-47. Disponível em: <http://www.ifla.org/VII/s42/pub/IL-Guidelines2006.pdf> [Consulta: 15 jan. 2012].

LICEA DE ARENAS, J; GÓMEZ HERNÁNDEZ, J.A. y VALLES VALENZUELA, J. Más sobre alfabetización informacional. ACIMED, 2009, vol. 20, nº 6, p. 216-227.

MARZAL, M.A. Investigación para la formación de bibliotecarios y documentalistas en alfabetización en información: un doctorado en la Universidad Carlos III de Madrid. Boletín de la ANABAD, 2004, vol. 54, $\mathrm{n}^{\circ}$ 1-2, p. $765-781$.

MARZAL, M.A. Evolución conceptual de alfabetización en información desde la alfabetización en su perspectiva educativa y bibliotecaria. Investigación Bibliotecológica, 2009, vol. 23, nº 47, p. 129-160.

MATA, M.L. A inserção da competência informacional nos currículos dos cursos de Biblioteconomia no Brasil e nos cursos de Informação e Documentação na Espanha. Faculdade de Filosofia e Ciências, Universidade Estadual Paulista, 2014. Tese de Doutorado.

MOREIRO-GONZÁLEZ, J.A. et al. Desarrollo profesional y opinión sobre la formación recibida de los titulados universitarios en información y documentación de las universidades públicas de Madrid (2000-2005). El Profesional de la Información, 2008, vol. 17, n 3, p. 261-272.

PINTO, M. y URIBE TIRADO, A. Formarnos y autoformarnos en alfabetización informacional. Un programa de mentorización en bibliotecas universitarias-CRAI. Investigación bibliotecológica, 2010, vol. 24, nº 52, p. 53-95.

REBIUN. Aprendizaje e investigación, $2016 . \quad$ Disponível em: $<$ http://www.rebiun.org/aprendizajeInvestigacion/Paginas/default.aspx > [Consulta: 21 fev. 2016].

SIMEÃO, E.L.M.S. y BELLUZZO, R.C.B. Competência em informação: teoria e práxis. Brasília: Universidade de Brasília, 2015. Disponível em: <https://issuu.com/necfci-unb/docs/compet_ncia_em_informa_o $>$ [Consulta: 10 mar. 2016].

SPECIAL LIBRARIES ASSOCIATION. Competencies for information professionals of the 21st Century. Special Committe on Competencies for Special Librarians, 2003 Disponível em: <http://www.sla.org/aboutsla/competencies/> [Consulta: 13 nov. 2014]. 
TEJADA ARTIGAS, C.; CHACÓN JARÉN, S. y MOREIRO-GONZÁLEZ, J.A. Mercado de trabajo en información y documentación y crisis económica en España: una aproximación a partir de las ofertas publicadas en IweTel entre 2008 y 2013. Bid: textos universitaris de biblioteconomia i documentació, 2014, $\mathrm{n}^{\mathrm{o}}$ 32. Disponivel em: $<$ http://bid.ub.edu/es/32/tejada2.htm $>$ [Consulta: 13 nov. 2014].

THE ECONOMIST INTELLIGENCE UNIT REPORT. Foresight 2020: Economic, industry and corporate trends. $2006 . \quad$ Disponível em: $<$ http://www2.warwick.ac.uk/fac/soc/csgr/green/foresight/economy/the_economist_intelligence_unit_full_report.p df> [Consulta: 13 abr. 2014].

URIBE TIRADO, A. Interrelaciones entre veinte definiciones-descripciones del concepto de alfabetización en información: propuesta de macro-definición. ACIMED, 2009, vol. 20, nº 4, p. 1-22. 